Can self-transcendent positive emotions facilitate bonds with nature?

\author{
Sam G. Moreton
}

School of Psychology, University of Wollongong, Wollongong, NSW, 2522 


\begin{abstract}
Self-transcendent positive emotions play a foundational role in social cognition through binding humans to others. In this article, theoretical and emerging empirical evidence is presented in support of the hypothesis that self-transcendent positive emotions may also facilitate bonds with the natural world. This is suggested to occur due to the ability of self-transcendent emotions to direct attention away from the self, facilitate connections with novel social targets, and reduce defensive distancing from nature caused by death anxiety and disgust. It is concluded that further research is needed to clarify the effects of discrete self-transcendent emotions on connectedness to nature, as well as the magnitude and duration of these effects.
\end{abstract}




\section{Can self-transcendent positive emotions facilitate bonds with nature?}

“...when we focus on others, our world expands. Our own problems drift to the periphery of the mind and so seem smaller, and we increase our capacity for connection". Daniel Goleman, Social Intelligence: The New Science of Human Relationships

To combat the growing threat of climate change, there needs to be a fundamental shift in how humans relate with the natural world. Although many factors determine pro-environmental behavior, research now suggests that one key determinant is the subjective relationship of the individual with the natural world. A range of constructs have been developed in the literature to capture related facets of this relationship (Tam, 2013a). The overarching construct is referred to here as connectedness to nature, although terms such as nature relatedness (Nisbet, Zelenski, \& Murphy, 2009) and inclusion of nature in self (Schultz, 2002) have also been used.

Connectedness to nature can be conceptualized as a broad construct involving both cognitive (a perception of the self as part of nature) and emotional (an affective bond with nature) elements (Tam, 2013a).

Most research to date into connectedness to nature has been correlational, with crosssectional designs utilized to investigate relationships between trait levels of connectedness to nature and a range of psychological and behavioral outcomes. Guided by theoretical considerations, connectedness to nature is often treated as a predictor or mediator variable, rather than an outcome variable. Yet, while it is important to understand the outcomes of connectedness to nature, it is also important to identify its origins. As connectedness to nature appears to play a key role in determining pro-environmental behavior (Schultz et al., 2005), psychologists with an interest in mitigating the impact of environmental threats must continue to develop further understanding of how connectedness to nature might be facilitated. To this end, a growing amount of research has investigated antecedent factors influencing connectedness to nature. The 
present article reviews theoretical and emerging empirical evidence suggesting that selftranscendent positive emotions typically increase feelings of connectedness to nature.

\section{Connectedness to nature and well-being}

A growing amount of theorists argue that connectedness to nature is a basic human need (Baxter \& Pelletier, 2018), with some suggesting it can also satisfy other fundamental needs such as identity, belonging and meaning-in-life (Howell, Passmore, \& Buro, 2013; Mayer, Frantz, Bruehlman-Senecal, \& Dolliver, 2009; Passmore \& Howell, 2014). If this is the case, higher levels of connectedness to nature should predict well-being. This hypothesis is well supported empirically with connectedness to nature being consistently linked with various facets of psychological well-being (Capaldi, Dopko, \& Zelenski, 2014; Pritchard, Richardson, Sheffield, \& McEwan, 2019).

Yet, as acknowledged by Capaldi et al. (2014), it is possible that some proportion of the shared variance between connectedness to nature and psychological well-being may be due to a reverse causal pathway: well-being might cause feelings of connectedness to nature. Many theorists have discussed the effects of positive emotions elicited by nature (Emerson, 1836; Joye \& Bolderdijk, 2015; Shiota, Keltner, \& Mossman, 2007) and the role of these emotions in the development of connectedness to nature (Kals, Schumacher, \& Montada, 1999). The present article extends this line of thought by suggesting that certain discrete positive emotions may increase feelings of connectedness to nature, even if they are not elicited by nature. In line with a social functionalist approach to emotions (see Keltner \& Haidt, 1999), which proposes that discrete positive emotions have distinct effects on human motivation and cognition (Griskevicius, Shiota, \& Neufeld, 2010a; Shiota et al., 2017), it is hypothesized that not all positive emotions may lead to increases in connectedness to nature. Rather, emotions with the 
evolved function to bind individuals to others may be particularly effective at facilitating connectedness to nature.

\section{Motivations towards nature}

In order to establish this hypothesis, it is useful to begin with a discussion of existing theoretical perspectives on the determinants of attitudes towards nature. Humanity's relationship with nature is complex — although many psychologists have recently argued that humans have a basic need to connect to nature (Baxter \& Pelletier, 2018), many theorists have also suggested that humans are often motivated to deny their animalistic selves and the continuity of humanity with nature (Becker, 1973; Freud, 1930; Goldenberg et al., 2001). This motivation has arguably become embedded in many major religious traditions. For instance, a key feature of Christian theology that can be traced at least as far back as the Protestant Reformation is what Metzner (1995) calls the "dissociative split between spirit and nature" (p.65). To achieve spiritual purity, mainstream Christianity argues that we must seek to transcend our base nature. While spirit pulls us upwards towards transcendence (the Heavens), our Earthly nature pulls us downwards towards degradation and Hell (Metzner, 1995). Similar themes emerge cross-culturally with many traditions ordering entities on a social dimension of "divinity" with pure entities such as saints at one end and degraded humans and animals at the other (Haidt, 2003; Haidt \& Algoe, 2004; Rozin, Lowery, Imada, \& Haidt, 1999).

A tension between a higher self and a base unconscious animalistic self was also touched upon by Freud (1930) who suggested that the animal nature of the id must be repressed by the ego in order for people to be able to function in a civilized manner. In suggesting this, Freud condemns modern "civilized" humans to an eternally conflicted relationship with our animal selves; namely, that we possess unconscious, animalistic desires which we cannot ever fully 
admit to, even to ourselves. This idea that humans can be motivated to deny their continuity with the animal kingdom can also be seen in the works of Ernst Becker $(1973,1975)$ who argued that considering ourselves as a part of the natural world makes us vulnerable to existential anxiety. If animals do not have spirits, and live transient, meaningless lives, then accepting ourselves as just another species opens up the possibility that our existence is ultimately meaningless.

These ideas have been adopted and expanded by terror management theorists (see Goldenberg, Cox, Pyszczynski, Greenberg, \& Solomon, 2002; Goldenberg et al., 2001) who argue that humans have developed a range of strategies to deny the fact that we are "breathing pieces of defecating meat no more significant or enduring than porcupines or peaches" (Solomon, 2008). Becker's hypothesis of a link between nature and death anxiety was supported by Goldenberg et al. (2001) who found that mortality salience increased disgust responses to animals and made people more likely to consider humans as distinct from animals. Furthermore, Goldenberg et al. (2002) found that participants primed with mortality salience expressed more negativity towards the physical (i.e. animalistic), but not romantic, aspects of sexual intercourse. Koole and Van den Berg (2005) also found that wild nature inspired thoughts of death and that priming death awareness led participants to rate wild natural environments as less beautiful. Similarly, Vess, Arndt, and Cox (2012) also found that priming mortality salience decreased connectedness to nature for people higher in religious fundamentalism. In sum, nature is often associated with fear, disgust and death (also see Bixler \& Floyd, 1997) and, these negative associations can exacerbate psychological dissociations from nature.

Motivations to associate with nature. Yet, while humans have motivations to psychologically dissociate from nature, we are also motivated to affiliate with nature (Baxter \& 
Pelletier, 2018). Wilson (1984) argues that humans are innately drawn to the natural world: an argument extended by many recent authors who claim that a psychological connection with nature is a fundamental human need. Passmore and Howell (2014) suggest that, rather than plunging us into existential despair, developing a connection with nature can actually help resolve existential anxieties. Mirroring the positive relationship between connectedness to nature and well-being (Capaldi et al., 2014; Cleary, Fielding, Bell, Murray, \& Roiko, 2017), exposure to nature has also been found to facilitate positive emotionality and psychological growth. Nature can induce feelings of peace (Herzog \& Strevey, 2008), vitality (Ryan et al., 2010; Takayama et al., 2014), awe (Keltner \& Haidt, 2003; Shiota et al., 2007), spiritual experiences (Terhaar, 2009), and transcendence (Williams \& Harvey, 2001). Natural environments are common stimuli for what Maslow $(1961,1962)$ termed "peak experiences": moments of transcendent joy which he argued play a key role in self-actualization. In line with Maslow's thinking that peak experiences can help build better people, exposure to beautiful nature can also elicit pro-social behavior (Zhang, Piff, Iyer, Koleva, \& Keltner, 2014), help people reflect on life problems (Mayer et al., 2009) and connect them with intrinsic aspirations (Weinstein, Przybylski, \& Ryan, 2009). Evidently, not only do people often respond positively to nature but affiliating with nature can facilitate personal growth.

The dual role that defense and growth motivations play in guiding attitudes towards nature in many ways mirrors human social motivations. For instance, social connectedness is a fundamental human need (Baumeister \& Leary, 1995), yet people will dissociate from other humans for reasons including the maintainance of self-esteem (Greenberg, Landau, Kosloff, Soenke, \& Solomon, 2016) and avoidance of moral contamination (Cottrell \& Neuberg, 2005). As with human social motivations, it appears evident that people have competing motivations to 
connect and dissociate from nature. Koole and Van den Berg (2004) suggest that defensive responses to nature may tend to predominate due to evolutionary pressures leading to a negativity bias (see Baumeister, Bratslavsky, Finkenauer, \& Vohs, 2001). Following Deci and Ryan (2000), they suggest that the activation of defense mechanisms may short-circuit growthoriented responding to nature. They also speculate that certain psychological mechanisms may shield nature-related growth motivations from being undermined by self-defense motivations. In the subsequent sections, it is argued that certain positive emotions may minimize defensive distancing from the natural world and facilitate connectedness to nature.

\section{The broaden-and-build theory of positive emotions}

According to the broaden and build theory (Fredrickson, 1998, 2001), positive emotions are not associated with specific action tendencies but instead function to broaden people's thought-action repertoires and build personal resources. Fredrickson (2001) suggests that positive emotions undo the effects of negative emotions by interrupting preparation for specific actions (e.g. fight, flight). This undoing effect is one mechanism through which positive emotions may facilitate connectedness to nature. Koole and Van den Berg (2004) suggest that negative emotions increase the likelihood of defensive responding to nature. If positive emotions can undo the effects of negative emotions, then they may be able to reduce threat-induced defensive distancing from nature.

But which positive emotions might we expect to demonstrate the strongest effect on connectedness to nature? Although the broaden-and-build theory suggests that positive emotions have shared functions, it does not rule out discrete positive emotions from having unique effects on cognition and behavior (see Fredrickson \& Branigan, 2005). A substantial amount of research has now demonstrated the utility of studying emotions from a functional perspective (Shiota et 
al., 2017). Discrete positive emotions lead to markedly different outcomes depending on the evolved function of the emotion (Griskevicius et al., 2010a; Keltner \& Haidt, 1999). From this perspective, positive emotions broaden and build in emotion-specific domains (Griskevicius, Shiota, \& Nowlis, 2010b).

\section{The social functions of emotions}

Social functionalist accounts of emotions suggest that many emotions evolved to help us navigate the social milieu (Fischer \& Manstead, 2008). From this perspective, many emotions have the dual function of informing the individual about a current social situation as well as preparing them to respond appropriately (Keltner \& Haidt, 1999). One class of emotions that has received recent attention within a social functionalist framework are the self-transcendent positive emotions (Stellar et al., 2017). These are emotions which arise from positive appraisals of entities outside the self and for this reason many of these emotions have been termed the other-praising emotions (Algoe \& Haidt, 2009). Stellar et al. (2017) propose a taxonomy of selftranscendent positive emotions categorized into three broad families: the emotion of awe and related emotions of moral elevation, inspiration, and admiration; compassion and related emotions of sympathy, love, and pity; and gratitude and the related emotion of appreciation. These emotion groups serve functional roles by respectively regulating behavior pertaining to group coordination, caretaking, and cooperation. As such, all of these emotions are involved in the development and maintenance of social relationships and can be considered to play foundational roles in human social cognition (Stellar et al., 2017).

Supporting the conceptualization of self-transcendent positive emotions as fundamentally pro-social emotions, many of these emotions have been found to induce broad feelings of social connectedness and induce pro-social behavior (Freeman, Aquino, \& McFerran, 2009; Oliver et 
al., 2015; Shiota et al., 2007). Of particular relevance to the present article is that the effects of self-transcendent positive emotions on feelings of connection have been found to carry over to novel individuals and groups. For instance, moral elevation (an awe-like emotion induced by witnessing moral excellence; Haidt, 2003) has been found to improve attitudes towards a range of outgroups even if the emotion was not elicited by a member of the relevant outgroup (Freeman et al., 2009; Lai, Haidt, \& Nosek, 2013; Oliver et al., 2015). Similarly, awe induced by nature has been found to increase feelings of connection to all humanity (Van Cappellen \& Saroglou, 2012b) and induce pro-social behavior (Piff, Dietze, Feinberg, Stancato, \& Keltner, 2015). Gratitude can also lead to pro-social behavior towards novel others - a phenomenon known as "upstream gratitude" (DeSteno, Li, Dickens, \& Lerner, 2014; Nowak \& Roch, 2007). In sum, the effects of self-transcendent positive emotions appear to not be limited to strengthening the relationship between the person who is experiencing the emotion and the entity which elicited it. Rather, the effects of these emotions appear to generalize and induce similar attitudes and motivations towards others that are not the source of the emotion. As such, these emotions tend to lead to broad feelings of connectedness to humanity (Bai et al., 2017; CarhartHarris, Erritzoe, Haijen, Kaelen, \& Watts, 2018; Janicke \& Oliver, 2017; Van Cappellen \& Saroglou, 2012b; Yaden et al., 2018).

\section{The role of social cognition in connectedness to nature}

In light of the above, might the effects of self-transcendent emotions also carry over to facilitate connectedness to nature? Convergent theorizing from different research groups suggests that social processes which guide cognition and behavior towards other humans may also inform attitudes towards the natural world (Costello \& Hodson, 2014; Dhont, Hodson, Costello, \& MacInnis, 2014; Epley, Akalis, Waytz, \& Cacioppo, 2008a; Epley, Schroeder, \& 
Waytz, 2013; Epley, Waytz, Akalis, \& Cacioppo, 2008b). For instance, the Interspecies Model of Prejudice (Costello \& Hodson, 2014) suggests that shared factors (e.g. social dominance orientation; Dhont et al., 2014) influence prejudice towards both human outgroups and animals. Social cognition is also involved in anthropomorphism (Epley et al., 2008a) with Epley, Waytz, and Cacioppo (2007) suggesting that, as anthropomorphism involves generalizing from humans to non-humans, the same processes that guide the attribution of mental states to humans are involved in the attribution of mental states to non-human agents. People can also form specific attachment relationships with animals (Zilcha-Mano, Mikulincer, \& Shaver, 2012) and include pets in their self-concept just as they do family members and friends (Aron, Aron, \& Smollan, 1992). Relationships with animals can also offset the negative effects of interpersonal loneliness and social exclusion (Aydin et al., 2012; Brown, Hengy, \& McConnell, 2016), suggesting that relationships with animals can serve a similar function to social relationships.

The role of social processes in perceptions of animals can also be seen at the neural level. For instance, viewing animals can activate the posterior superior temporal sulcus (Chao, Haxby, \& Martin, 1999; Kaiser, Shiffrar, \& Pelphrey, 2012): a brain hub that plays a large role in the processing of social information (Lahnakoski et al., 2012). Similar neural mechanisms have been implicated in responses to animal and human suffering (Filippi et al., 2010; Franklin et al., 2013) and oxytocin (a peptide implicated in the attribution of mental states to humans; Barraza \& Zak, 2009; Hurlemann et al., 2010) has also been found to increase the incidence of anthropomorphism (Scheele et al., 2015).

Social cognition also appears to be involved in people's attitudes towards plants. For instance, people often form para-social relationships with plants such as large trees (Hill, 2000; Sommer, 2003) and a human tendency to anthropomorphize trees can be seen throughout many 
religious traditions (e.g. Japanese tree spirits; Kato, 2008) as well as throughout literature (e.g. the Lord of the Rings; Tolkien, 1963). Many cultures have stories of trees turning into humans or humans into trees - a tendency perhaps due to the fact that trees bear some physical resemblance with the human form (e.g. head/canopy, trunk/body, roots/feet; Sommer, 2001).

Furthermore, connectedness to nature as a whole resembles a social relationship as both involve inclusion of the other in the self (Schultz, 2002), positive emotions towards the other (Kals et al., 1999; Perkins, 2010) and a commitment to protect the other (Davis, Green, \& Reed, 2009). A cognitive identification with nature has also been suggested to serve a similar function to social identities insofar as it can also help satisfy needs for identity and relatedness (Clayton, 2003; Mayer et al., 2009; Passmore \& Howell, 2014). Nature as a whole can also be anthropomorphized (e.g. Mother Earth) and Tam, Lee, and Chao (2013) provide evidence that anthropomorphism of nature increases feelings of connectedness to nature.

In sum, social processes are implicated in people's relationships with nature. To the extent that this is the case, the fact that the effects of these self-transcendent positive emotions appear to generalize to novel social targets suggests that they may also facilitate closeness with animals, plants, and nature as a whole. The following section discusses additional reasons for why self-transcendent positive emotions are hypothesized to facilitate connectedness to nature.

\section{Death, disgust, and the boundaries of the self}

A pathway through which self-transcendent positive emotion may facilitate connectedness to nature is through reducing the defensive distancing from nature that occurs due to death anxiety and the emotion of disgust (Goldenberg et al., 2001; Koole \& Van den Berg, 2005). Mikulincer, Florian, and Hirschberger (2003) suggest that the overlapping sense of self caused by feelings of connection may facilitate a transcending of the "biological boundaries of 
one's existence" as one's sense of self has been expanded to include a loved one. They suggest that close relationships may provide a "symbolic shield" against the terror of death. These ideas have been given empirical support with Hart, Shaver, and Goldenberg (2005) finding that secure attachment was associated with less defensive responding when primed with mortality salience. Furthermore, feeling socially disconnected appears to increase death anxiety. For instance, Steele, Kidd, and Castano (2014) and Yaakobi (2018) both found ostracized participants had increased death-thought accessibility. These findings all converge on the conclusion that feelings of social connectedness can buffer death anxiety. As self-transcendent positive emotions lead to feelings of social connectedness, people who regularly experience self-transcendent positive emotions may have a stronger death anxiety buffer, and as such may be less likely to defensively deidentify with the natural world.

By drawing others into the moral circle, many self-transcendent positive emotions can be considered the functional opposites of disgust: an emotion that activates behavioral avoidance and psychological dissociation from the disgust-eliciting stimuli (Sherman \& Haidt, 2011). Disgust appears to play a role in fear responses to animals (Muris, Mayer, Huijding, \& Konings, 2008; Webb \& Davey, 1992) and has been suggested to motivate a denial of humanity's place in nature. As eloquently stated by Buckels and Trapnell (2013, p. 2): “...disgust guards the humananimal boundary in social cognition, playing the dual role of distancing ourselves from "lower" creatures and reaffirming our own humanity" (also see Goldenberg et al., 2001). It is plausible that positive emotions which are the functional opposites to disgust may be the most effective at suppressing the disgust response and lead to improved attitudes towards entities that elicit disgust (see Lai et al., 2013). As discussed by Sherman and Haidt (2011), there are a number of self-transcendent positive emotions which can be considered the functional opposites to disgust 
such as moral elevation, compassion, love, and gratitude. While there has been minimal research directly testing whether these emotions can directly reduce experienced disgust, Lai et al. (2013) found that moral elevation reduced homophobia: a phenomenon linked to feelings of disgust (Inbar, Pizarro, \& Bloom, 2012). Due to the role that disgust plays in maintaining a psychological boundary between humanity and the natural world, it is plausible that selftranscendent emotions may facilitate a breaking down of this boundary through suppressing the effects of disgust. This may lead to a heightened identification with nature as a whole, as well as improved attitudes towards disgust-inducing animals and environments (e.g. pigs, rats, swamps).

An additional pathway through which self-transcendent positive emotions may facilitate connectedness to nature is through blurring boundaries of the self. Haidt and Morris (2009) suggest that self-transcendent emotions are largely unique among positive emotions in that they shift attentional focus away from the self and towards others (also see Bai et al., 2017; Shiota et al., 2007). In reviewing the literature on self-transcendent experiences, Yaden, Haidt, Hood Jr, Vago, and Newberg (2017) suggest that self-transcendence experiences often involve the disappearance of a sense of self - a phenomenon also termed ego-dissolution (Nour, Evans, Nutt, \& Carhart-Harris, 2016). Pertinently, psychedelic drugs known to cause ego-dissolution have recently been found to increase feelings of connectedness to nature (Lyons \& CarhartHarris, 2018). Interestingly, the extent to which psychedelic users experience ego-dissolution during psychedelic experiences has also been found to predict feelings of connectedness to nature (Nour, Evans, \& Carhart-Harris, 2017). Further, attention directed to the self has been linked with decreased connectedness to nature (Frantz, Mayer, Norton, \& Rock, 2005). Due to their effects in directing attention away from a clearly demarked self, many self-transcendent 
positive emotions may have a unique ability among positive emotions to blur the boundary of the self from the external world, which may lead to heightened connectedness to nature.

To summarize, this article has discussed four related reasons for why self-transcendent positive emotions may increase connectedness to nature. First, as social processes are involved in people's relationships with nature, the ability of self-transcendent positive emotions to generate generalized feelings of connectedness towards third-parties implies that they may generate feelings of connectedness to nature. Second, the fact that self-transcendent positive emotions increase feelings of social connectedness suggests they may reduce death anxiety and thus reduce the defensive distancing from nature caused by terror-management defenses. Third, as many self-transcendent positive emotions are plausible candidates to be considered functional opposites of disgust, they may be able to improve attitudes towards disgust-eliciting entities and reduce the defensive distancing from nature caused by common associations between nature and disgust. Fourth, these emotions may be able to increase connectedness to nature through reduced focus on a self clearly demarked from the external world.

\section{Emerging empirical evidence that social emotions can facilitate connectedness to nature}

Despite these theoretical considerations, little empirical research to date has investigated the effects of any positive emotions on connectedness to nature, let along investigated the relative effects of discrete positive emotions.

A strong contender among the self-transcendent positive emotions for increasing connectedness to nature is awe: a quintessential spiritual emotion (Keltner \& Haidt, 2003). Yet, although there is evidence that awe instills feelings of connectedness to other humans (see Saroglou, Buxant, \& Tilquin, 2008; Van Cappellen \& Saroglou, 2012a; Yaden et al., 2018), it is less clear whether awe which is not induced by nature leads to increased connectedness to nature. 
However, recent work by Yang, Hu, Jing, and Nguyen (2018) found that awe increased connectedness to nature, even when awe was not elicited by nature, but rather was elicited by other humans. These studies provide some of the most direct evidence to date linking selftranscendent positive emotions to connectedness to nature. However, the effects of awe on connectedness to nature may depend on the valence of the emotion (see Gordon et al., 2017for a review of the dark side of awe). For instance, recent work by Hornsey, Faulkner, Crimston, and Moreton (2018) found no main effects of threat-based awe experiences (exposure to the enormity of the universe and lava fields) on connectedness to nature and identification with all humanity. It is plausible that threat-based awe may actually activate defensive distancing from nature in some people through activating terror management defenses.

Nevertheless, positive awe experiences which lead to broad social connectedness are likely to induce connectedness to nature. In this regard, moral elevation is a less threatening awerelated emotion which has also been suggested to be the functional opposite of disgust (Sherman \& Haidt, 2011) and is thus a strong contender for increasing connectedness to nature. Along these lines, recent work by Moreton, Arena, Hornsey, Crimston, and Tiliopoulos (2019) found across two studies that moral elevation increased feelings of connectedness to nature. These findings provide further evidence for the role of social cognition in connectedness to nature, and, along with Yang et al. (2018) provide the most direct evidence suggesting that self-transcendent positive emotions can facilitate connectedness to nature.

However, although this research suggests that awe and related emotions may increase connectedness to nature, no published research to date has investigated whether other social emotions may help facilitate bonds with the natural world. For instance, the emotions of gratitude and appreciation are other strong contenders to increase connectedness to nature. 
Although gratitude likely evolved to help facilitate patterns of interpersonal reciprocity, gratitude can also be felt towards non-human entities. For instance, theologians and philosophers have discussed the concept of cosmic gratitude: feelings of gratitude which extend to God or, for atheists, to the universe as a whole (Roberts, 2014). Philosophers have also more specifically discussed the concept of gratitude towards nature (e.g. Bardsley, 2013), with Hursthouse (2007) considering it a key environmental virtue.

To the author's best knowledge, the only empirical research to date specifically looking at gratitude to nature has been Naito et al. (2010), who found that gratitude towards nature was linked with pro-environmental behavior. However, no published research has investigated whether interpersonal gratitude can carry over to facilitate gratitude towards nature. In providing a comprehensive review of the gratitude literature, Wood, Froh, and Geraghty (2010) suggest that gratitude involves more than "...recognition and reciprocation of interpersonal aid; with gratitude drawing attention to the perception of anything to appreciate in the world (p.3, emphasis added). If this is the case, then it is plausible that feelings of interpersonal gratitude may extend outwards to facilitate feelings of gratitude towards the natural world. These feelings of gratitude may then facilitate attachment and identification with nature.

For the reasons discussed in this article, it is also plausible that emotions from the “caretaking" family of self-transcendent positive emotions (e.g. compassion, love) may also have carry-over effects on connectedness to nature. Although Pfattheicher, Sassenrath, and Schindler (2016) provided correlational and experimental evidence suggesting that compassion for other humans can increase pro-environmental behavior, they did not actually measure whether compassion for other humans led to compassion, or connectedness, to nature. As the authors note "it is an open question whether compassion promotes proenvironmental tendencies as an ultimate 
goal, that is, whether compassionate individuals anthropomorphize nature and benefit nature as an agent...or whether compassion promotes proenvironmental tendencies as an instrumental goal, that is, whether compassionate individuals benefit nature to benefit the lives of others." (p. 939). Nevertheless, in line with the present article, the authors also suggest that as incidental emotions can carry over to other situations, then compassion for humans may carry over to facilitate compassion for the natural world.

As compassion is an emotion which facilitates connectedness, heightened compassion for nature should be expected to lead to connectedness to nature. Indeed, Tam (2013b) found empathy with nature to be related to connectedness to nature, and suggested that the former may increase the latter. Supporting this, although not directly testing the effects of compassion, Aspy and Proeve (2017) found significant positive effects of loving-kindness meditation on connectedness to nature. The authors did not measure self-transcendent positive emotions as potential mediators; however, in line with the present article, they suggest compassion as one plausible mediating mechanism. In sum, although there is indirect evidence suggesting that compassion may facilitate compassion for, and subsequent connectedness to, nature, further research is needed to clarify this causal relationship.

A related emotion involved in caretaking is the cuteness response (which has also been referred to as "aww"; Buckley, 2016). Supporting the conceptualization of the cuteness response as an emotion which expands the moral circle (Sherman \& Haidt, 2011), recent work suggests that cuteness in animals facilitates their moral inclusion (Piazza, McLatchie, \& Olesen, 2018; Zickfeld, Kunst, \& Hohle, 2018). Interestingly, Sherman and Chandler (2012) found that the cuteness response induced by baby humans and animals carried over to heightened desires to interact with, and anthropomorphize, technological gadgets. It is plausible that a similar carry- 
over effect may exist whereby cuteness not induced by any aspect of nature may facilitate connection with animals and nature as a whole.

In sum, there are a range of social emotions which appear likely to have carry-over effects on connectedness to nature. Yet, potential effects of asocial positive emotions on connectedness to nature are less clear. As all positive emotions may undo the effects of negative emotions to some extent (Fredrickson, 2001), it is possible that all positive emotions may exert some effect on connectedness to nature through reducing defensive responses to nature associated with negative emotions (Koole \& Van den Berg, 2004). Yet, less plausible candidates for increasing connectedness to nature are those positive emotions which do not (a) induce prosocial motivations; (b) reduce death anxiety; (c) suppress disgust; and/or (d) reduce focus on the self. One illustrative example in this regard would be hubristic pride which involves attention directed to an inflated self (van Osch, Zeelenberg, \& Breugelmans, 2018) and increased emotional distancing from distant others (Ashton-James \& Tracy, 2012). As such, it is plausible that hubristic pride may enhance feelings of separateness from the natural world. Future research testing the effects of positive emotions on connectedness to nature would do well to continue the common practice of comparing the effects of discrete positive emotions which have theoretically distinct evolved functions.

\section{May self-transcendent positive emotions have enduring effects on connectedness to nature?}

Despite there being a strong theoretical rationale for the hypothesis that self-transcendent positive emotions may temporarily increase connectedness to nature, it is less clear whether these effects may persist over longer time periods. Fredrickson (2001) suggests that positive emotions tend to beget positive emotions, thus creating an upward spiral of improved well-being involving more frequent experiences of positive emotions. Therefore, it is plausible that this upward spiral 
may cause a parallel rise in connectedness to nature. Nevertheless, it is also possible that people may feel connected to nature while experiencing a self-transcendent positive emotion but these feelings may simply "fizzle out" with the emotion.

However, indirect evidence for an enduring effect of powerful self-transcendent experiences comes from recent research into the psychological effects of psychedelic drugs. Supporting anecdotal evidence of users (Masters \& Houston, 1966), recent evidence suggests that these substances may have enduring effects on connectedness to nature. For instance, Forstmann and Sagioglou (2017) found in a large population sample $(N=1487)$ that lifetime use of psychedelics was linked with increased connectedness to nature. Although these data are correlational, corroborating experimental evidence for a causal effect of psychedelics on connectedness to nature has been provided by Lyons and Carhart-Harris (2018) who found that patients with treatment-resistant depression who were treated with psilocybin (the active component in "magic mushrooms") had increases in connectedness to nature after one week and, crucially, that these effects persisted for 7-12 months.

As psychedelic drugs are known to induce self-transcendent states (Griffiths et al., 2011; Griffiths, Richards, McCann, \& Jesse, 2006) involving increased sociality (Dolder, Schmid, Müller, Borgwardt, \& Liechti, 2016), the effects of psychedelic drugs on connectedness to nature may in large part be due to induced self-transcendent positive emotions. Indeed, a recent paper by Hendricks (2018) argues that the emotion of awe may be a key mechanism underpinning the therapeutic effects of psychedelics. As such, burgeoning recent research into psychedelics suggests that intense experiences of self-transcendent positive emotions may have lasting effects on connectedness to nature. Yet, the specific psychological mechanisms behind the effects of psychedelics are still not well understood (Watts, Day, Krzanowski, Nutt, \& Carhart-Harris, 
2017) and, although Lyons and Carhart-Harris (2018) provide preliminary evidence that selftranscendent experiences may lead to persisting changes in connectedness to nature for some people, the robustness and generalizability of this effect is yet to be firmly established. Thus, the existence and persistence of effects of self-transcendent positive emotions on connectedness to nature remains largely uncharted territory.

\section{Conclusion}

This article has reviewed evidence suggesting that that self-transcendent positive emotions may facilitate connectedness to nature, even if they are not elicited by nature. Due to the strong link between connectedness to nature and pro-environmental behavior, this hypothesis also implies that self-transcendent positive emotions may increase pro-environmental behavior. As such, the present article has implications for interventions aimed at increasing connectedness to nature and pro-environmental behavior amongst urban dwellers. In an ideal world, connectedness to nature could be developed through adequate public access to beautiful nature. Yet, many people in modern societies do not have this luxury and strategies for fostering connectedness to nature which do not rely upon exposure to nature have a role to play in combatting environmental threats. As anthropogenic climate change is arguably the greatest challenge facing humanity in the coming decades, it is critical that greater understanding is developed of causal influences on connectedness to nature. Although the emerging research into the role of social emotions is promising, further research is needed to establish the magnitude and duration of the effects of different self-transcendent positive emotions on connectedness to nature. 


\section{References}

Algoe, S. B., \& Haidt, J. (2009). Witnessing excellence in action: The 'other-praising'emotions of elevation, gratitude, and admiration. The Journal of Positive Psychology, 4(2), 105127.

Aron, A., Aron, E. N., \& Smollan, D. (1992). Inclusion of other in the self scale and the structure of interpersonal closeness. Journal of Personality and Social Psychology, 63(4), 596.

Ashton-James, C. E., \& Tracy, J. L. (2012). Pride and prejudice: How feelings about the self influence judgments of others. Personality and Social Psychology Bulletin, 38(4), 466476.

Aspy, D. J., \& Proeve, M. (2017). Mindfulness and Loving-Kindness Meditation: Effects on Connectedness to Humanity and to the Natural World. Psychological reports, 120(1), 102-117.

Aydin, N., Krueger, J. I., Fischer, J., Hahn, D., Kastenmüller, A., Frey, D., \& Fischer, P. (2012). "Man's best friend:" How the presence of a dog reduces mental distress after social exclusion. Journal of Experimental Social Psychology, 48(1), 446-449.

Bai, Y., Maruskin, L. A., Chen, S., Gordon, A. M., Stellar, J. E., McNeil, G. D., Peng, K., \& Keltner, D. (2017). Awe, the diminished self, and collective engagement: Universals and cultural variations in the small self. Journal of Personality and Social Psychology, $113(2), 185$.

Bardsley, K. (2013). Mother nature and the mother of all virtues: On the rationality of feeling gratitude toward nature. Environmental Ethics, 35(1), 27-40.

Barraza, J. A., \& Zak, P. J. (2009). Empathy toward strangers triggers oxytocin release and subsequent generosity. Annals of the New York Academy of Sciences, 1167(1), 182-189.

Baumeister, R. F., Bratslavsky, E., Finkenauer, C., \& Vohs, K. D. (2001). Bad is stronger than good. Review of general psychology, 5(4), 323.

Baumeister, R. F., \& Leary, M. R. (1995). The need to belong: Desire for interpersonal attachments as a fundamental human motivation. Psychological Bulletin, 117(3), 497529.

Baxter, D. E., \& Pelletier, L. (2018). Is Nature Relatedness a Basic Human Psychological Need? A Critical Examination of the Extant Literature.

Becker, E. (1973). The denial of death: New York, Free Press.

Becker, E. (1975). Escape from evil: New York, NY, US: Free Press.

Bixler, R. D., \& Floyd, M. F. (1997). Nature is scary, disgusting, and uncomfortable. Environment and Behavior, 29(4), 443-467.

Brown, C. M., Hengy, S. M., \& McConnell, A. R. (2016). Thinking about cats or dogs provides relief from social rejection. Anthrozoös, 29(1), 47-58.

Buckels, E. E., \& Trapnell, P. D. (2013). Disgust facilitates outgroup dehumanization. Group Processes \& Intergroup Relations, 16(6), 771-780.

Buckley, R. C. (2016). Aww: The emotion of perceiving cuteness. Frontiers in Psychology, 7 , 1740.

Capaldi, C. A., Dopko, R. L., \& Zelenski, J. M. (2014). The relationship between nature connectedness and happiness: A meta-analysis. Frontiers in Psychology, 5, 976.

Carhart-Harris, R., Erritzoe, D., Haijen, E., Kaelen, M., \& Watts, R. (2018). Psychedelics and connectedness. Psychopharmacology, 235(2), 547-550. 
Chao, L. L., Haxby, J. V., \& Martin, A. (1999). Attribute-based neural substrates in temporal cortex for perceiving and knowing about objects. Nature neuroscience, 2(10), 913.

Clayton, L. W. (2003). Identity and the natural environment: The psychological significance of nature: Mit Press.

Cleary, A., Fielding, K. S., Bell, S. L., Murray, Z., \& Roiko, A. (2017). Exploring potential mechanisms involved in the relationship between eudaimonic wellbeing and nature connection. Landscape and urban planning, 158, 119-128.

Costello, K., \& Hodson, G. (2014). Explaining dehumanization among children: The interspecies model of prejudice. British Journal of Social Psychology, 53(1), 175-197.

Cottrell, C. A., \& Neuberg, S. L. (2005). Different emotional reactions to different groups: a sociofunctional threat-based approach to" prejudice". Journal of Personality and Social Psychology, 88(5), 770.

Davis, J. L., Green, J. D., \& Reed, A. (2009). Interdependence with the environment: Commitment, interconnectedness, and environmental behavior. Journal of Environmental Psychology, 29(2), 173-180.

Deci, E. L., \& Ryan, R. M. (2000). The" what" and" why" of goal pursuits: Human needs and the self-determination of behavior. Psychological Inquiry, 11(4), 227-268.

DeSteno, D., Li, Y., Dickens, L., \& Lerner, J. S. (2014). Gratitude A Tool for Reducing Economic Impatience. Psychological Science, 0956797614529979.

Dhont, K., Hodson, G., Costello, K., \& MacInnis, C. C. (2014). Social dominance orientation connects prejudicial human-human and human-animal relations. Personality and Individual Differences, 61, 105-108.

Dolder, P. C., Schmid, Y., Müller, F., Borgwardt, S., \& Liechti, M. E. (2016). LSD acutely impairs fear recognition and enhances emotional empathy and sociality. Neuropsychopharmacology, 41(11), 2638.

Emerson, R. W. (1836). Nature and selected essays: Penguin.

Epley, N., Akalis, S., Waytz, A., \& Cacioppo, J. T. (2008a). Creating social connection through inferential reproduction: Loneliness and perceived agency in gadgets, gods, and greyhounds. Psychological Science, 19(2), 114-120.

Epley, N., Schroeder, J., \& Waytz, A. (2013). Motivated mind perception: Treating pets as people and people as animals Objectification and (De) Humanization (pp. 127-152): Springer.

Epley, N., Waytz, A., Akalis, S., \& Cacioppo, J. T. (2008b). When we need a human: Motivational determinants of anthropomorphism. Social Cognition, 26(2), 143-155.

Epley, N., Waytz, A., \& Cacioppo, J. T. (2007). On seeing human: a three-factor theory of anthropomorphism. Psychological review, 114(4), 864.

Filippi, M., Riccitelli, G., Falini, A., Di Salle, F., Vuilleumier, P., Comi, G., \& Rocca, M. A. (2010). The brain functional networks associated to human and animal suffering differ among omnivores, vegetarians and vegans. PloS one, 5(5), e10847.

Fischer, A. H., \& Manstead, A. S. (2008). Social functions of emotion. Handbook of emotions, 3, 456-468.

Forstmann, M., \& Sagioglou, C. (2017). Lifetime experience with (classic) psychedelics predicts pro-environmental behavior through an increase in nature relatedness. Journal of Psychopharmacology, 31(8), 975-988. 
Franklin, R. G., Nelson, A. J., Baker, M., Beeney, J. E., Vescio, T. K., Lenz-Watson, A., \& Adams Jr, R. B. (2013). Neural responses to perceiving suffering in humans and animals. Social neuroscience, 8(3), 217-227.

Frantz, C., Mayer, F. S., Norton, C., \& Rock, M. (2005). There is no "I" in nature: The influence of self-awareness on connectedness to nature. Journal of Environmental Psychology, 25(4), 427-436.

Fredrickson, B. L. (1998). What good are positive emotions? Review of general psychology, 2(3), 300.

Fredrickson, B. L. (2001). The role of positive emotions in positive psychology: The broadenand-build theory of positive emotions. American Psychologist, 56(3), 218.

Fredrickson, B. L., \& Branigan, C. (2005). Positive emotions broaden the scope of attention and thought - action repertoires. Cognition \& Emotion, 19(3), 313-332.

Freeman, D., Aquino, K., \& McFerran, B. (2009). Overcoming beneficiary race as an impediment to charitable donations: Social dominance orientation, the experience of moral elevation, and donation behavior. Personality and Social Psychology Bulletin, 35(1), 72-84.

Freud, S. (1930). Civilisation and its discontents. Civilization and its discontents, 64-145.

Goldenberg, J. L., Cox, C. R., Pyszczynski, T., Greenberg, J., \& Solomon, S. (2002). Understanding human ambivalence about sex: The effects of stripping sex of meaning. Journal of sex research, 39(4), 310-320.

Goldenberg, J. L., Pyszczynski, T., Greenberg, J., Solomon, S., Kluck, B., \& Cornwell, R. (2001). I am not an animal: Mortality salience, disgust, and the denial of human creatureliness. Journal of Experimental Psychology: General, 130(3), 427.

Gordon, A. M., Stellar, J. E., Anderson, C. L., McNeil, G. D., Loew, D., \& Keltner, D. (2017). The dark side of the sublime: Distinguishing a threat-based variant of awe. Journal of Personality and Social Psychology, 113(2), 310.

Greenberg, J., Landau, M. J., Kosloff, S., Soenke, M., \& Solomon, S. (2016). How our means for feeling transcendent of death fosster prejudice, stereotyping, and intergroup conflict: Terror management theory. Handbook of prejudice, stereotyping, and discrimination, 107-148.

Griffiths, R. R., Johnson, M. W., Richards, W. A., Richards, B. D., McCann, U., \& Jesse, R. (2011). Psilocybin occasioned mystical-type experiences: immediate and persisting doserelated effects. Psychopharmacology, 218(4), 649-665.

Griffiths, R. R., Richards, W. A., McCann, U., \& Jesse, R. (2006). Psilocybin can occasion mystical-type experiences having substantial and sustained personal meaning and spiritual significance. Psychopharmacology, 187(3), 268-283.

Griskevicius, V., Shiota, M. N., \& Neufeld, S. L. (2010a). Influence of different positive emotions on persuasion processing: A functional evolutionary approach. Emotion, 10(2), 190.

Griskevicius, V., Shiota, M. N., \& Nowlis, S. M. (2010b). The many shades of rose-colored glasses: An evolutionary approach to the influence of different positive emotions. Journal of Consumer Research, 37(2), 238-250.

Haidt, J. (2003). Elevation and the positive psychology of morality. In J. Haidt \& C. Keyes (Eds.), Flourishing: Positive psychology and the life well-lived (Vol. 275, pp. 275-289). Washington, DC: Am. Psychol. Assoc. 
Haidt, J., \& Algoe, S. (2004). Moral amplification and the emotions that attach us to saints and demons. Handbook of experimental existential psychology, 322-335.

Haidt, J., \& Morris, J. P. (2009). Finding the self in self-transcendent emotions. Proceedings of the National Academy of Sciences, pnas. 0903076106.

Hart, J., Shaver, P. R., \& Goldenberg, J. L. (2005). Attachment, self-esteem, worldviews, and terror management: evidence for a tripartite security system. Journal of Personality and Social Psychology, 88(6), 999.

Hendricks, P. S. (2018). Awe: a putative mechanism underlying the effects of classic psychedelic-assisted psychotherapy. International Review of Psychiatry, 1-12.

Herzog, T. R., \& Strevey, S. J. (2008). Contact with nature, sense of humor, and psychological well-being. Environment and Behavior, 40(6), 747-776.

Hill, J. B. (2000). The legacy of Luna: the story of a tree, a woman, and the struggle to save the Redwoods: Harper San Francisco San Francisco, Ca.

Hornsey, M. J., Faulkner, C., Crimston, D., \& Moreton, S. (2018). A microscopic dot on a microscopic dot: Self-esteem buffers the negative effects of exposure to the enormity of the universe. Journal of Experimental Social Psychology, 76, 198-207.

Howell, A. J., Passmore, H.-A., \& Buro, K. (2013). Meaning in nature: Meaning in life as a mediator of the relationship between nature connectedness and well-being. Journal of Happiness Studies, 14(6), 1681-1696.

Hurlemann, R., Patin, A., Onur, O. A., Cohen, M. X., Baumgartner, T., Metzler, S., Dziobek, I., Gallinat, J., Wagner, M., \& Maier, W. (2010). Oxytocin enhances amygdala-dependent, socially reinforced learning and emotional empathy in humans. Journal of Neuroscience, 30(14), 4999-5007.

Hursthouse, R. (2007). Environmental virtue ethics. Working virtue: Virtue ethics and contemporary moral problems, 155-171.

Inbar, Y., Pizarro, D. A., \& Bloom, P. (2012). Disgusting smells cause decreased liking of gay men. Emotion, 12(1), 23.

Janicke, S. H., \& Oliver, M. B. (2017). The relationship between elevation, connectedness, and compassionate love in meaningful films. Psychology of Popular Media Culture, 6(3), 274.

Joye, Y., \& Bolderdijk, J. W. (2015). An exploratory study into the effects of extraordinary nature on emotions, mood, and prosociality. Frontiers in Psychology, 5, 1577.

Kaiser, M. D., Shiffrar, M., \& Pelphrey, K. A. (2012). Socially tuned: brain responses differentiating human and animal motion. Social neuroscience, 7(3), 301-310.

Kals, E., Schumacher, D., \& Montada, L. (1999). Emotional affinity toward nature as a motivational basis to protect nature. Environment and Behavior, 31(2), 178-202.

Kato, K. (2008). Addressing global responsibility for conservation through cross-cultural collaboration: Kodama Forest, a forest of tree spirits. The Environmentalist, 28(2), 148154.

Keltner, D., \& Haidt, J. (1999). Social functions of emotions at four levels of analysis. Cognition \& Emotion, 13(5), 505-521.

Keltner, D., \& Haidt, J. (2003). Approaching awe, a moral, spiritual, and aesthetic emotion. Cognition \& Emotion, 17(2), 297-314.

Koole, S. L., \& Van den Berg, A. E. (2004). Paradise lost and reclaimed: An existential motives analysis of human-nature relations. Handbook of experimental existential psychology, 86103. 
Koole, S. L., \& Van den Berg, A. E. (2005). Lost in the wilderness: terror management, action orientation, and nature evaluation. Journal of Personality and Social Psychology, 88(6), 1014.

Lahnakoski, J. M., Glerean, E., Salmi, J., Jääskeläinen, I. P., Sams, M., Hari, R., \& Nummenmaa, L. (2012). Naturalistic FMRI mapping reveals superior temporal sulcus as the hub for the distributed brain network for social perception. Frontiers in human neuroscience, 6, 233.

Lai, C. K., Haidt, J., \& Nosek, B. A. (2013). Moral elevation reduces prejudice against gay men. Cognition \& Emotion(ahead-of-print), 1-14.

Lyons, T., \& Carhart-Harris, R. L. (2018). Increased nature relatedness and decreased authoritarian political views after psilocybin for treatment-resistant depression. Journal of Psychopharmacology, 0269881117748902.

Maslow, A. H. (1961). Peak experiences as acute identity experiences. The American Journal of Psychoanalysis, 21(2), 254-262.

Maslow, A. H. (1962). Lessons from the peak-experiences. Journal of humanistic psychology, 2(1), 9-18.

Masters, R., \& Houston, J. (1966). The varieties of psychedelic experience: The classic guide to the effects of LSD on the human psyche: Simon and Schuster.

Mayer, F. S., Frantz, C. M., Bruehlman-Senecal, E., \& Dolliver, K. (2009). Why is nature beneficial? The role of connectedness to nature. Environment and Behavior, 41(5), 607643.

Metzner, R. (1995). The psychopathology of the human-nature relationship. Ecopsychology: Restoring the earth, healing the mind, 55-67.

Mikulincer, M., Florian, V., \& Hirschberger, G. (2003). The existential function of close relationships: Introducing death into the science of love. Personality and Social Psychology Review, 7(1), 20-40.

Moreton, S. G., Arena, A., Hornsey, M., Crimston, C., \& Tiliopoulos, N. (2019). Elevating nature: moral elevation increases feelings of connectedness to nature. Journal of Environmental Psychology, 65, 101332.

Muris, P., Mayer, B., Huijding, J., \& Konings, T. (2008). A dirty animal is a scary animal! Effects of disgust-related information on fear beliefs in children. Behaviour research and therapy, 46(1), 137-144.

Naito, T., Matsuda, T., Intasuwan, P., Chuawanlee, W., Thanachanan, S., Ounthitiwat, J., \& Fukushima, M. (2010). Gratitude for, and regret toward, nature: Relationships to proenvironmental intent of university students from Japan. Social Behavior and Personality: an international journal, 38(7), 993-1008.

Nisbet, E. K., Zelenski, J. M., \& Murphy, S. A. (2009). The nature relatedness scale linking individuals' connection with nature to environmental concern and behavior. Environment and Behavior, 41(5), 715-740.

Nour, M. M., Evans, L., \& Carhart-Harris, R. L. (2017). Psychedelics, personality and political perspectives. Journal of psychoactive drugs, 49(3), 182-191.

Nour, M. M., Evans, L., Nutt, D., \& Carhart-Harris, R. L. (2016). Ego-dissolution and psychedelics: validation of the ego-dissolution inventory (EDI). Frontiers in human neuroscience, 10, 269.

Nowak, M. A., \& Roch, S. (2007). Upstream reciprocity and the evolution of gratitude. Proceedings of the Royal Society of London B: Biological Sciences, 274(1610), 605-610. 
Oliver, M. B., Kim, K., Hoewe, J., Chung, M. Y., Ash, E., Woolley, J. K., \& Shade, D. D. (2015). Media - induced elevation as a means of enhancing feelings of intergroup connectedness. Journal of Social Issues, 71(1), 106-122.

Passmore, H.-A., \& Howell, A. J. (2014). Eco-existential positive psychology: Experiences in nature, existential anxieties, and well-being. The Humanistic Psychologist, 42(4), 370388.

Perkins, H. E. (2010). Measuring love and care for nature. Journal of Environmental Psychology, 30(4), 455-463.

Pfattheicher, S., Sassenrath, C., \& Schindler, S. (2016). Feelings for the suffering of others and the environment: Compassion fosters proenvironmental tendencies. Environment and Behavior, 48(7), 929-945.

Piazza, J., McLatchie, N., \& Olesen, C. (2018). Are Baby Animals Less Appetizing? Tenderness toward Baby Animals and Appetite for Meat. Anthrozoös, 31(3), 319-335.

Piff, P. K., Dietze, P., Feinberg, M., Stancato, D. M., \& Keltner, D. (2015). Awe, the small self, and prosocial behavior. Journal of Personality and Social Psychology, 108(6), 883.

Pritchard, A., Richardson, M., Sheffield, D., \& McEwan, K. (2019). The Relationship Between Nature Connectedness and Eudaimonic Well-Being: A Meta-Analysis. Journal of Happiness Studies, 1-23.

Roberts, R. C. (2014). Cosmic gratitude. European Journal for Philosophy of Religion, 6, 65-83.

Rozin, P., Lowery, L., Imada, S., \& Haidt, J. (1999). The CAD triad hypothesis: a mapping between three moral emotions (contempt, anger, disgust) and three moral codes (community, autonomy, divinity). Journal of Personality and Social Psychology, 76(4), 574.

Ryan, R. M., Weinstein, N., Bernstein, J., Brown, K. W., Mistretta, L., \& Gagne, M. (2010). Vitalizing effects of being outdoors and in nature. Journal of Environmental Psychology, 30(2), 159-168.

Saroglou, V., Buxant, C., \& Tilquin, J. (2008). Positive emotions as leading to religion and spirituality. The Journal of Positive Psychology, 3(3), 165-173.

Scheele, D., Schwering, C., Elison, J. T., Spunt, R., Maier, W., \& Hurlemann, R. (2015). A human tendency to anthropomorphize is enhanced by oxytocin. European Neuropsychopharmacology, 25(10), 1817-1823.

Schultz, P. W. (2002). Inclusion with nature: The psychology of human-nature relations. In P. Schmuck, \& Schultz, W.P. (Ed.), Psychology of Sustainable Development (pp. 61-78). Dordrecht: Kluwer Academic Publishers.

Schultz, P. W., Gouveia, V. V., Cameron, L. D., Tankha, G., Schmuck, P., \& Franěk, M. (2005). Values and their relationship to environmental concern and conservation behavior. Journal of Cross-Cultural Psychology, 36(4), 457-475.

Sherman, G., \& Chandler, J. (2012). Cuteness cues elicit anthropomorphism. Unpublished manuscript, Harvard University.

Sherman, G. D., \& Haidt, J. (2011). Cuteness and disgust: The humanizing and dehumanizing effects of emotion. Emotion Review, 3(3), 245-251.

Shiota, M. N., Campos, B., Oveis, C., Hertenstein, M. J., Simon-Thomas, E., \& Keltner, D. (2017). Beyond happiness: Building a science of discrete positive emotions. American Psychologist, 72(7), 617.

Shiota, M. N., Keltner, D., \& Mossman, A. (2007). The nature of awe: Elicitors, appraisals, and effects on self-concept. Cognition and Emotion, 21(5), 944-963. 
Solomon, S. (2008). Fear, Death, and Politics: What Your Mortality Has to Do with the Upcoming Election. Interview by Jonah Lehrer. Scientific American, 23.

Sommer, R. (2001). The Dendro-Psychoses of JO Quantz. Journal of Arboriculture, 27(1).

Sommer, R. (2003). Trees and human identity. Identity and the natural environment: The psychological significance of nature, 179-204.

Steele, C., Kidd, D. C., \& Castano, E. (2014). On Social Death: Ostracism and the Accessibility of Death Thoughts. Death studies(ahead-of-print), 1-5.

Stellar, J. E., Gordon, A. M., Piff, P. K., Cordaro, D., Anderson, C. L., Bai, Y., Maruskin, L. A., \& Keltner, D. (2017). Self-transcendent emotions and their social functions: Compassion, gratitude, and awe bind us to others through prosociality. Emotion Review, 9(3), 200-207.

Takayama, N., Korpela, K., Lee, J., Morikawa, T., Tsunetsugu, Y., Park, B.-J., Li, Q., Tyrväinen, L., Miyazaki, Y., \& Kagawa, T. (2014). Emotional, restorative and vitalizing effects of forest and urban environments at four sites in Japan. International Journal of Environmental Research and Public Health, 11(7), 7207-7230.

Tam, K.-P. (2013a). Concepts and measures related to connection to nature: Similarities and differences. Journal of Environmental Psychology, 34, 64-78.

Tam, K.-P. (2013b). Dispositional empathy with nature. Journal of Environmental Psychology, 35, 92-104.

Tam, K.-P., Lee, S.-L., \& Chao, M. M. (2013). Saving Mr. Nature: Anthropomorphism enhances connectedness to and protectiveness toward nature. Journal of Experimental Social Psychology, 49(3), 514-521.

Terhaar, T. L. (2009). Evolutionary Advantages of Intense Spiritual Experience in Nature. Journal for the Study of Religion, Nature \& Culture, 3(3).

Tolkien, J. R. R. (1963). The Lord of the Rings: In 3 Vols.

Van Cappellen, P., \& Saroglou, V. (2012a). Awe activates religious and spiritual feelings and behavioral intentions. Psychology of Religion and Spirituality, 4(3), 222-236.

Van Cappellen, P., \& Saroglou, V. (2012b). Awe activates religious and spiritual feelings and behavioral intentions. Psychology of Religion and Spirituality, 4(3), 223.

van Osch, Y., Zeelenberg, M., \& Breugelmans, S. M. (2018). The self and others in the experience of pride. Cognition and Emotion, 32(2), 404-413.

Vess, M., Arndt, J., \& Cox, C. R. (2012). Faith and Nature The Effect of Death-Relevant Cognitions on the Relationship Between Religious Fundamentalism and Connectedness to Nature. Social Psychological and Personality Science, 3(3), 333-340.

Watts, R., Day, C., Krzanowski, J., Nutt, D., \& Carhart-Harris, R. (2017). Patients' accounts of increased "connectedness" and "acceptance" after psilocybin for treatment-resistant depression. Journal of humanistic psychology, 57(5), 520-564.

Webb, K., \& Davey, G. C. (1992). Disgust sensitivity and fear of animals: Effect of exposure to violent or revulsive material. Anxiety, Stress and Coping, 5(4), 329-335.

Weinstein, N., Przybylski, A. K., \& Ryan, R. M. (2009). Can nature make us more caring? Effects of immersion in nature on intrinsic aspirations and generosity. Personality and Social Psychology Bulletin, 35(10), 1315-1329.

Williams, K., \& Harvey, D. (2001). Transcendent experience in forest environments. Journal of Environmental Psychology, 21(3), 249-260.

Wilson, E. O. (1984). Biophilia. Massachusetts: Harvard University Press.

Wood, A. M., Froh, J. J., \& Geraghty, A. W. (2010). Gratitude and well-being: A review and theoretical integration. Clinical Psychology Review, 30(7), 890-905. 
Yaakobi, E. (2018). Death thoughts mediate ostracism mood reduction: The moderating role of marital status. Motivation and Emotion, 1-10.

Yaden, D. B., Haidt, J., Hood Jr, R. W., Vago, D. R., \& Newberg, A. B. (2017). The varieties of self-transcendent experience. Review of general psychology, 21(2), 143.

Yaden, D. B., Kaufman, S. B., Hyde, E., Chirico, A., Gaggioli, A., Zhang, J. W., \& Keltner, D. (2018). The development of the Awe Experience Scale (AWE-S): A multifactorial measure for a complex emotion. The Journal of Positive Psychology, 1-15.

Yang, Y., Hu, J., Jing, F., \& Nguyen, B. (2018). From awe to ecological behavior: The mediating role of connectedness to nature. Sustainability, 10(7), 2477.

Zhang, J. W., Piff, P. K., Iyer, R., Koleva, S., \& Keltner, D. (2014). An occasion for unselfing: Beautiful nature leads to prosociality. Journal of Environmental Psychology, 37, 61-72.

Zickfeld, J. H., Kunst, J. R., \& Hohle, S. M. (2018). Too sweet to eat: Exploring the effects of cuteness on meat consumption. Appetite, 120, 181-195.

Zilcha-Mano, S., Mikulincer, M., \& Shaver, P. R. (2012). Pets as safe havens and secure bases: The moderating role of pet attachment orientations. Journal of Research in Personality, 46(5), 571-580. 